\title{
Ignácio Rangel: Ciclos Longos, Dualidade, e um Depoimento Pessoal
}

\section{Ignácio Rangel: Long Cycles and Duality}

Luiz Carlos Bresser-Pereira*

\begin{abstract}
Resumo: Para Ignácio Rangel, o desenvolvimento econômico é um movimento intrinsecamente contraditório, através do qual a inovação tecnológica, cuja dinâmica explica o ciclo longo, está em permanente conflito com os capitais existentes que são por ela depreciados. O desenvolvimento no Brasil não é simplesmente a oposição de um setor capitalista e outro pré-capitalista; existe também uma dualidade externa que não apenas expressa a relação entre suas fases de crescimento econômico e o desenvolvimento da economia mundial, mas também mostra como os setores moderno e atrasado conflitam em cada etapa. A dualidade tem um duplo caráter: através da coexistência de relações de produção que correspondem a duas fases históricas sequenciais, e através da existência, no mercado doméstico e no "polo" externo de tal dualidade, uma relação de dependência para as sociedades mais avançadas.
\end{abstract}

Palavras-chave: Dualidade. Desenvolvimento. Relações de produção. Ciclos longos.

Abstract. For Ignácio Rangel economic development is an intrinsically contradictory movement through which technological innovation, whose dynamics explains the long cycle, is permanently in conflict with the existing capitals that it depreciates. Development in Brazil is not just defined by the opposition between the capitalist and the pre-capitalist sector; there is also an external duality that does not just express the relation between its stages of economic growth and the development of the world economy, but also tells us how its modern and its backward sector change at each stage. The duality has a double character: through the coexistence of relations of productions that correspond to two sequential historical phases, and through the existence, in the domestic and in the external "pole" of such duality, a relation of dependency toward the more advanced societies.

Keywords: Duality. Development. Relations of production. Long cycles.

JEL Classification: B15; O17; $\mathrm{O} 31$.

Professor emérito da Fundação Getúlio Vargas. E-mail: bresserpereira@gmail.com. Site: www. bresserpereira.org.br. Agradeço a José Márcio Rego pelos comentários. 


\section{Introdução}

Vivemos um tempo de transição do capitalismo desencadeado pela crise financeira global de 2008. Os belos 30 Anos Dourados do Capitalismo, após a Segunda Guerra Mundial, foram seguidos pelos tristes 30 Anos Neoliberais do Capitalismo. A fase B do ciclo de Kondratieff que começou, no plano econômico, em 1973, e no plano político, em 1979, parece afinal estar chegando ao fim com esta grande crise. Não vou neste trabalho analisá-la. Já o fiz em um outro trabalho (2010). Pareceu-me, entretanto, o momento de voltar ao pensamento de um dos meus mestres, Ignácio Rangel, e discutir suas ideias sobre os ciclos longos e a dualidade, porque elas são relevantes para compreendermos o presente incerto em que vivemos, e porque no trabalho mais amplo que José Márcio Rego e eu dedicamos à sua obra, quando ele ainda estava vivo (1993), a parte relativa à dualidade não estava bem desenvolvida.

Ignácio Rangel e Celso Furtado foram os dois mais notáveis economistas brasileiros do século XX. Rangel era dotado de uma inteligência penetrante e de uma poderosa imaginação que lhe permitiram analisar de forma inovadora a economia brasileira e, ao mesmo tempo, contribuir para o desenvolvimento da teoria econômica. Eu o conheci na segunda metade dos anos 50, quando li seus trabalhos sobre a capacidade ociosa e o desenvolvimento, e assisti a suas conferências no Instituto Superior de Estudos Brasileiros (Iseb). Desde então ele foi para mim um mestre e um pouco mais tarde um amigo. Em 1963, quando publicou A Inflação Brasileira, discutimos seu livro em um seminário que então Antonio Delfim Netto organizava na Faculdade de Economia da USP. Delfim criticava Rangel pela imprecisão de seus conceitos econômicos, mas intuía que ali estava um grande economista autodidata que, naquele livro, estava formulando uma interpretação inovadora sobre a inflação brasileira. Embora Rangel não conhecesse a obra de Kalecki, ele desenvolvia uma macroeconomia com as classes sociais e a taxa de lucro. Por outro lado, em seu livro sobre a inflação ele tornara claro algo que em Keynes estava apenas sugerido: que a oferta de moeda é endógena, de forma que o Banco Central está longe de ter o poder que se lhe atribui de controlá-la. ${ }^{1} \mathrm{~A}$ teoria da inflação inercial entendeu a oferta de moeda essencialmente como um fenômeno endógeno, como o fator por excelência "sancionador da inflação". Hoje, a teoria econômica oficial é obrigada a reconhecer que a oferta de moeda é essencialmente endógena. A esperança dos economistas que estudam a moeda e a dos bancos centrais que a administram é o de, através do ajuste fiscal e da obtenção de uma poupança pública substancial, lograrem uma razoável exogeneidade da política monetária. Mas, como mostrou

$1 \quad$ Mais precisamente, conforme um parecerista anônimo me lembrou, no Treatise on Money Keynes afirmou que ela era endógena, ao passo que na Teoria Geral ele foi menos específico. 
Rangel, especialmente em situações em que a inflação é elevada, esse objetivo é inalcançável.

Rangel foi um economista formado pelo pensamento marxista, o keynesiano e pela escola estruturalista da Cepal. Nos anos 50, esse pensamento está dominado pela ideia de planejamento econômico. Exagerava-se naquela época a importância do planejamento, da mesma forma que hoje se as subestima. O próprio Rangel chegou a escrever um livro sobre o tema (Elementos de Economia do Projetamento, 1958). Não obstante, sua atitude em relação à economia e à política econômica era profundamente contrária ao voluntarismo. Talvez a sua mais profunda convicção tenha sido a de que a economia tem uma dinâmica própria, cíclica, não se submetendo facilmente às políticas das autoridades econômicas.

Ignácio Rangel foi um dos primeiros economistas a pensar o desenvolvimento econômico em termos macroeconômicos. Seus conhecimentos de teoria econômica eram limitados, mas tinham bases intelectuais sólidas, fundadas em Marx, Keynes e Schumpeter. Bases que, submetidas à sua imensa capacidade de enfrentar o pensamento convencional, o lugar comum, as "verdades" hegemônicas neoclássicas, o tornavam, ao mesmo tempo, heterodoxo e extraordinário. Em muitas ocasiões, Rangel desenvolveu ideias que confrontavam o saber convencional, não apenas o saber convencional dos economistas conservadores, mas também, senão principalmente, dos economistas de esquerda, estruturalistas ou marxistas como ele.

Um exemplo dessa sua heterodoxia radical está na chamada "curva de Rangel”, mostrando que no longo prazo a inflação tem uma relação inversa - ao invés de direta, como pretende a teoria convencional - com o crescimento. Rangel (1985) demonstrou que no Brasil, desde os anos 50, quanto maior o crescimento, menor a inflação, e vice-versa. Rangel nunca deu uma explicação completa para esse fato, mas está claro que isto acontece no médio prazo na medida em que a inflação é um sintoma da crise, que é um mecanismo de defesa da economia contra a própria crise. No curto prazo, o excesso de demanda pode provocar inflação, mas, em um prazo mais longo, o que eleva a taxa inflacionária é a incapacidade da economia de resolver adequadamente suas próprias contradições, resultando daí a relação inversa. Para "resolver" os desequilíbrios dos preços relativos que a crise provoca, a inflação é a forma mais fácil que o sistema econômico descontrolado encontra.

Tornei-me amigo de Ignácio Rangel nos anos 70. Com o golpe militar de 1964, ele foi compulsoriamente aposentado do BNDES. Por algum tempo, permaneceu no ostracismo, até que, em 1972, vem a São Paulo participar da reunião da SBPC, e traz um artigo baseado na teoria dos ciclos de Kondratieff. Nesse artigo, previa que em breve a economia mundial entraria em uma grande crise, embora naquele momento no Brasil vivêssemos em ritmo de milagre, e no resto do mundo as taxas 
de crescimento continuassem muito favoráveis. Lembro-me da desconfiança que as ideias de Rangel provocaram nos economistas presentes, mesmo nos economistas estruturalistas. Mais uma vez Rangel estava confrontando o saber convencional tanto neoclássico quanto estruturalista. Entretanto, no ano seguinte suas previsões se confirmavam ao desencadear-se a crise a partir do primeiro choque do petróleo de 1973. Nos vinte anos depois de 1973, as taxas de crescimento no primeiro mundo foram a metade do que foram nos vinte anos anteriores, e depois de 1993 continuaram inferiores às dos anos dourados do capitalismo.

Rangel sempre pensou na economia como sendo um processo histórico, cíclico e dialético. A ideia de que a economia tem dinâmica própria, que é determinada pelo mercado e pela tecnologia, não podendo ser alterada ao belprazer dos formuladores de política econômica, tem base em Marx, e foi sempre um dos traços marcantes do seu pensamento. A inflação não era para ele mera consequência de descontrole do gasto público, mas uma forma através da qual a economia se defende da tendência cíclica à capacidade ociosa. Além disso, era o resultado do poder monopolista das grandes empresas vendedoras e compradoras que aumentavam suas margens e em seguida as mantinham rígidas, mesmo em caso de recessão.

Formado em Direito pela Universidade do Maranhão, onde nasceu, seu único estudo formal de economia foi um curso, em meados dos anos 50, na Comissão Econômica para América Latina. Isso não impediu, entretanto, que, da mesma forma que criticava as interpretações ortodoxas da inflação (monetaristas e keynesianas), criticasse também as teorias estruturalistas que via como insuficientes para explicar a inflação brasileira.

Ignácio Rangel foi sempre um homem de esquerda. A militância comunista e lhe custou a prisão em 1936. Já no Rio de Janeiro, nos anos 1940 e 1950, tornou-se um nacionalista desenvolvimentista, preocupado com o grande projeto nacional de industrializar o Brasil. Para isso, participou da fundação do Iseb, uma instituição que repensou o Brasil de forma radical nos anos 50 e definiu seu grande projeto de desenvolvimento. No Instituto Superior de Estudos Brasileiros Ignácio Rangel foi o grande economista, enquanto Hélio Jaguaribe era o grande cientista político, e Guerreiro Ramos o grande sociólogo. Nesse instituto, do qual também participaram Cândido Mendes de Almeida, Álvaro Vieira Pinto, Roland Corbisier, Nelson Werneck Sodré, e, perifericamente, Celso Furtado, reuniu-se um grande grupo de intelectuais nacionalistas - o Grupo de Itatiaia - que fez a crítica do modelo primário-exportador e da alienação cultural das elites oligárquicas, semiaristocráticas, ligadas a terra e ao comércio exterior, ao mesmo tempo que propunha a estratégia nacional-desenvolvimentista: a industrialização por substituição de importações através de uma grande aliança política da classe industrial burguesa nascente, da tecnoburocracia estatal orientada para o desenvolvimento, 
e dos trabalhadores urbanos. Rangel aceitou esse diagnóstico e essa estratégia, cujo principal formulador fora Hélio Jaguaribe, mas acrescentou que a aliança política industrializante só se tornaria realmente compreensível se aos industriais, aos burocratas e aos trabalhadores fosse acrescentada uma quarta classe à qual cabia a liderança política da coalizão política: a "oligarquia substituidora de importações”, existente no Sul e no Nordeste. Getúlio Vargas, que fora o grande líder político do início da industrialização brasileira, era um estancieiro, um membro da oligarquia substituidora de importações.

Rangel aprendeu com os grandes economistas políticos, mas, como acontece com todo grande intelectual, ele era um homem capaz de pensar por conta própria. Por isso abandonou muito cedo o comunismo. Por isso nunca pode ser enquadrado como um típico economista estruturalista, ou um típico economista keynesiano. Decididamente Rangel não foi um desses muitos epígonos que repetem um mestre qualquer: ele não estava voltado meramente para a produção da ciência normal. Ele era um criador que se arriscava ao inovar.

Rangel, além de economista teórico que publicou muitos livros, foi um homem de ação. Foi um dos membros da assessoria econômica de Getúlio Vargas presidida por Rômulo de Almeida em seu segundo governo, entre 1950 e 1954. Depois, foi economista do BNDES. Juntamente com seu grande amigo, Jesus Soares Pereira, teve um papel importante na criação das grandes empresas estatais brasileiras, particularmente a Petrobras e a Eletrobras, que teriam um papel tão decisivo no desenvolvimento do Brasil. Seu compromisso fundamental era com o desenvolvimento. Para alcançá-lo, não se deixava levar por ideologias de direita ou de esquerda. Para um país se desenvolver, o fundamental era investir. E investimentos só podiam ser realizados se financiados. Logo, pragmaticamente, buscava saber como seria possível financiar o desenvolvimento. Em certo momento, esse financiamento pode ser feito a partir dos fundos de poupança forçada do Estado. Estimulou essa forma de financiamento. Com a crise do início dos anos 60, essa fonte começou a exaurir-se. Propôs, então, a Octávio Gouvêa de Bulhões, na época ministro da Fazenda, a correção monetária como uma estratégia alternativa. Em meados dos anos 70, porém, a correção monetária começava a apresentar efeitos distorcivos, ao mesmo tempo que a capacidade de poupança forçada do Estado revelava-se definitivamente esgotada. ${ }^{2}$ Rangel volta a surpreender a todos ao ser o primeiro a propor a privatização das empresas estatais, que ele ajudara a criar. Em 1978, no posfácio da terceira edição de seu livro sobre a inflação, que eu, como seu amigo, o convenci a escrever, Rangel diagnosticava a crise do Estado e

2 Talvez porque a teoria da inflação esteja baseada na indexação formal e informal da economia, uma ideia da qual Rangel se julgava o principal idealizador no Brasil, ele nunca a aceitou e se mostrou sempre crítico a ela. Não obstante sua teoria da inflação como resposta à ociosidade e à crise econômica, ele tenha ajudado a inspirar os formuladores da teoria da inflação inercial certamente a mim. 
propunha que, através de uma nova lei de concessão de serviços públicos, o setor privado se responsabilizasse de forma crescente pelos investimentos públicos de infraestrutura.

Rangel era um homem preocupado com a distribuição de renda. Mas o respeito às tendências endógenas da economia - à lógica do ciclo econômico e dos movimentos de longo prazo da economia - era nele dominante. Por isso, quando nos anos 1950 e 1960 a reforma agrária foi transformada pela esquerda em uma condição sine qua non do desenvolvimento brasileiro, Rangel discordou. Era pessoalmente favorável à reforma agrária, mas observava que esta, que fora essencial nos países desenvolvidos para criar o mercado interno, não o era no Brasil em 1950, quando a indústria contava com o mercado cativo originado na substituição de importações.

Neste trabalho, além do testemunho pessoal que acabei de fazer, vou me ater a apenas dois aspectos das ideias de Rangel - à sua visão e aplicação ao Brasil da teoria dos ciclos longos e à sua teoria da dualidade básica, esta toda voltada para a economia brasileira. Escolhi esses temas porque são centrais para o seu pensamento, porque no trabalho que escrevi com José Márcio Rego sobre Rangel discutimos bem o problema dos ciclos longos, mas demos um tratamento incompleto ao da dualidade, e, principalmente, porque esses dois temas são hoje relevantes para a economia brasileira, há 26 anos semiestagnada. Vou fazer referência aos trabalhos originais de Rangel, mas, para um acesso à sua obra, a contribuição de César Benjamin, organizando suas Obras Reunidas (2005), foi de alta valia.

\section{Os Ciclos Longos}

Sua concepção do desenvolvimento econômico e político do Brasil está apoiada em duas ideias-chave: os ciclos longos e a dualidade básica. Os ciclos longos de Kondratieff são centrais em sua análise da evolução histórica de nossa economia e sociedade. Conforme ele afirmou,

O relacionamento que faço das vicissitudes de nossa história nacional com as ondas longas, cuja simples existência não é aceita mansamente, faz-me sentir um pouco como Heinrich Schliemann quando resolveu levar a sério a Ilíada, na busca da localização exata de Tróia, valorizando, assim, um documento que muitos consideravam uma tessitura de mitos. Assim, comecei por levar a sério a teoria das ondas longas, buscando com ela compaginar nossa própria história nacional.

3 Para uma discussão teórica sobre os ciclos longos de Kondratieff, ver Bresser Pereira (1986). A literatura sobre o tema desenvolveu-se extraordinariamente nos anos 1980, provavelmente a partir do fato de que a desaceleração das economias desenvolvidas, ocorrida a partir do início dos anos 1970, confirmou as previsões embutidas na teoria de Kondratieff. Para uma análise razoavelmente completa do assunto, ver Solomou (1990). 
E não duvido de que os estudos aprofundados, de outros pesquisadores, não apenas confirmarão minhas hipóteses, como lançarão nova luz sobre aquela teoria, fazendo progredir a ciência. (KONDRATIEFF, 1982, p. 11). ${ }^{4}$

Rangel aprendeu a teoria dos ciclos longos de Kondratieff lendo Business Cycles, de Schumpeter (1939), e o próprio texto de Kondratieff publicado em espanhol pela Revista de Occidente. ${ }^{5}$ Para Rangel, o processo de desenvolvimento é um processo eminentemente cíclico regido por ondas de inovação tecnológica e pelo processo de acumulação de capital. Rangel assinala, insistentemente, que esse processo cíclico independe da vontade humana, portanto, da política e do planejamento. É um processo contraditório através do qual a inovação tecnológica, cuja dinâmica explica o ciclo longo, está em permanente conflito com os capitais existentes que são por ela depreciados. A massa de recursos acumulados funciona como um fator de resistência ao progresso tecnológico, "devendo ser buscada aí a causação mais profunda das flutuações econômicas". A reversão cíclica ocorre porque, "a certa altura, em seguida a um período de intensa renovação do capital fixo, passam a preponderar as forças propensas à preservação dos capitais recémcriados, e a capacidade instalada encontra os limites do mercado" (RANGEL, 1981, p. 21).

Ciclos longos segundo Rangel (1981)

\begin{tabular}{ccc}
\hline Ciclos Longos & Fase "a" & Fase "b" \\
\hline 1 & $1870-1815$ & $1815-1847$ \\
2 & $1847-1873$ & $1873-1896$ \\
3 & $1896-1920$ & $1920-1948$ \\
4 & $1948-1973$ & $1973-(?)$ \\
\hline
\end{tabular}

Rangel utilizou intensamente a teoria dos ciclos longos para compreender o processo de desenvolvimento brasileiro. O paralelismo que Rangel faz entre as vicissitudes de nossa história econômica e política e os ciclos longos é sugestivo. As fases "b" dos ciclos, quando a economia se desacelera, embora mantendo taxas positivas de crescimento, é sempre identificada com mudanças marcantes na história brasileira. Com efeito, "na fase 'b' do $1^{\circ}$ Kondratieff, tivemos a Independência; na 'b' do $2^{\circ}$ deu-nos a Abolição-República; quanto à revolução de 30, que enquadraria institucionalmente a industrialização, foi, segundo todas as aparências, um incidente da fase 'b' do $3^{\circ}$ Kondratieff” (RANGEL, 1981, p. 19).

4 Segundo a Wikipedia, "Heinrich Schliemann (1822-1890) foi um arqueólogo clássico alemão, um defensor da realidade histórica dos topônimos mencionados nas obras de Homero e um importante descobridor de sítios arqueológicos micênicos, como Troia e a própria Micenas."

5 Ver Rangel (1981), onde ele examina a dinâmica dos ciclos de Kondratieff. O texto publicado por essa revista corresponde provavelmente a um capítulo de Kondratieff (1925 [1984]). 
No Brasil, ou seja, em uma economia periférica, as fases "b" ou recessivas dos ciclos longos "manifestam-se primordialmente pelo relativo estrangulamento do comércio exterior e pela piora dos termos de intercâmbio" (Ibid, p. 19). Como essa fase ocorre de forma sustentada por todo um quartel de século, as economias periféricas têm tempo para se ajustarem à nova situação. "No caso brasileiro, a economia tem encontrado sempre meios e modos de ajustar-se ativamente à conjuntura implícita no ciclo longo. Em especial, confrontada com o fechamento do mercado externo para os nossos produtos resultante da conjuntura declinante dos países cêntricos, temos reagido por uma forma qualquer de substituições de importações, ajustada ao nível de desenvolvimento de nossas forças produtivas e ao estado das nossas relações de produção" (Ibid, p. 19). Daí resultar que o nosso desenvolvimento econômico "dista muito de ser limitado às fases 'a' ou ascendentes dos ciclos longos. Nossa economia, confrontada com movimentos duradouros de fluxo e refluxo, em suas relações com o centro dinâmico universal, encontra meios de crescer 'para fora', expandindo a produção exportável, ou, 'para dentro', promovendo uma forma qualquer de substituições de importações" (Ibid, p. 20).

Ignácio Rangel não utilizou a teoria dos ciclos longos apenas para compreender o Brasil. Em 1972, quando o Brasil vivia seu "milagre" econômico e na economia mundial o primeiro choque do petróleo ainda não ocorrera, Rangel, que após o seu enfarte estava desaparecido, surpreendeu a todos quando previu a crise mundial a partir da dinâmica de Kondratieff. ${ }^{6}$ Rangel observa que em 1913 esgota-se a expansão do terceiro Kondratieff e começa um período depressivo, durante o qual se acumulavam precondições científicas para um novo ciclo de inovações tecnológicas. Essa fase recessiva dura até 1938, quando tem início uma nova onda de expansão que atravessa a Segunda Guerra Mundial e um período de intensa reconstrução. Entretanto, observa Rangel (1972, p. 116), temos,

[...] depois de 1963, período caracterizado por crescentes sintomas de que a "reconstrução ampliada" do pós-guerra foi chegando ao fim nas áreas decisivas do "centro dinâmico". Noutros termos, acumulam-se os indícios de que entramos numa era semelhante à que se seguiu a 1913 [...].

Durante os anos 1960 já começavam a se definir as condições para a reversão cíclica, a qual, entretanto, só se consumaria em 1973, quando começa a fase "b" do quarto Kondratieff. Em um artigo posterior, Rangel reconheceu esse fato. Equivocou-se, entretanto, em relação à sua repercussão sobre a economia

$6 \quad$ Este artigo foi apresentado em São Paulo, em julho de 1972, ao congresso anual da Sociedade Brasileira para o Progresso da Ciência. Entre outros, estavam na reunião Antônio Barros de Castro, Francisco de Oliveira e Paulo Singer. O artigo foi publicado no ano seguinte em Estudos Cebrap. 
brasileira, ao afirmar que "[...] a ideia de que a fase 'b' do ciclo longo signifique, necessariamente, para os países periféricos, uma queda do dividendo nacional, ou mesmo uma desaceleração do seu crescimento, deve ser liminarmente descartada" (RANGEL, 1981, p. 34). Rangel supunha que poderia novamente reproduzirse no Brasil a expansão que ocorrera na fase recessiva do terceiro Kondratieff, quando isso, de fato, já não podia ocorrer, já que aquela anomalia decorrera da possibilidade, necessariamente passageira, de se realizar uma industrialização substitutiva de importações.

$\mathrm{Na}$ verdade, não em 1973, mas em 1980, o Brasil entrou em uma fase de desaceleração econômica que demonstra que até hoje não saiu da fase "b" do quarto ciclo de Kondratieff. Nem o Brasil, nem a economia mundial, excetuados os países asiáticos dinâmicos. Nos anos 1990, depois do colapso da União Soviética, produziu-se certa euforia nos Estados Unidos que levou muitos economistas a afirmar que a economia mundial voltava a crescer com força. Enganavam-se, da mesma forma que a fase "b" do $3^{\circ}$ Kondratieff foi um tempo de liberalismo econômico radical, a fase " $b$ " do $4^{\circ}$ Kondratieff também o foi - foi o tempo que tenho denominado os Anos Neoliberais do Capitalismo. O que sugere que talvez fosse necessário pensar em associar a teoria das inovações de longo prazo de Schumpeter, que está associada aos ciclos de Kondratieff, à teoria da alternância de fases desenvolvimentistas e neoliberais no processo de desenvolvimento capitalista para entender sua dinâmica de longo prazo.

\section{Dualidade Básica}

Ignácio Rangel considerou a teoria da dualidade básica sua principal contribuição ao entendimento do Brasil. Estava apoiada na ideia dos ciclos longos, mas era uma teoria mais complexa e possuía um componente político e social mais desenvolvido. A partir de uma perspectiva histórica, Rangel desenvolve uma teoria que, abarcando as outras esferas da realidade social, tenta dar conta da especificidade da economia e da sociedade brasileiras. A dualidade a que se refere Rangel não é simplesmente a oposição de um setor capitalista e outro pré-capitalista. Para ele, não se trata apenas de verificar que o desenvolvimento da economia brasileira passa por etapas correspondentes ao desenvolvimento histórico da economia mundial, mas como o setor moderno e o atrasado conflitam e mudam em cada etapa.

A novidade analítica de Rangel consiste em afirmar, primeiro, a coexistência dual de relações de produção historicamente defasadas em relação às fases por que passaram as sociedades europeias; segundo, em mostrar que essa defasagem é dependente das relações de produção existentes na Europa; e, terceiro, em apresentar esse processo dual, defasado e dependente como encadeado: o polo 
"secundário" (ou externo) de uma dualidade transformando-se no polo "principal" (ou interno) da dualidade seguinte. Rangel chama os polos não de secundário e principal, mas de "externo" e "interno"; no entanto, como ele também detecta um "lado externo", em cada um desses polos, correspondente às relações de produção vigentes nos países centrais, preferimos usar as expressões polo "secundário" e polo "principal" (ao invés de "externo" e "interno") para tornar o modelo histórico mais claro. No polo principal, situam-se as relações de produção dominantes e a correspondente classe dominante, que ele chama de "sócio maior" do sistema. No polo secundário, situam-se as relações de produção emergentes e o correspondente sócio menor - a classe social que na dualidade seguinte transformar-seá no sócio maior. O polo principal corresponde, portanto, ao momento em que determinada classe é ainda dominante, mas que tende a ser superado na medida em que o sócio maior é deslocado da posição dominante, enquanto o polo secundário o é apenas porque o sócio menor ainda não ascendeu e se impôs à antiga classe dominante. A dualidade, assim, aparece duplamente: através da coexistência de relações de produção correspondentes a duas fases históricas sequenciais, e através da existência, nos dois polos, de uma relação de dependência com as sociedades mais avançadas do que o Brasil: tanto no polo principal quanto no secundário, o respectivo lado externo apresenta relações de produção atrasadas em comparação às vigentes na Europa e nos Estados Unidos. O caráter dual e dependente da economia e da sociedade brasileira fica, assim, claro, integrado, e assume um caráter dinâmico.

A dinâmica histórica brasileira distingue-se, portanto, dos casos clássicos, porque os processos sociais, econômicos e políticos não decorrem apenas da interação entre desenvolvimento das forças produtivas e relações de produção internas ao país, mas também da evolução das relações que este mantém com as economias centrais. Conforme observa Rangel (1957, p. 36-37):

Embora seja mais fácil surpreender o fato da dualidade no estudo de um instituto particular do que na economia nacional como um todo, é evidente que a sua origem se encontra nas relações externas. Desenvolvendo-se como economia complementar ou periférica, o Brasil deve ajustar-se a uma economia externa diferente da sua, de tal sorte que é, ele próprio, uma dualidade. Os termos dessa dualidade se alteram e desde logo podemos assinalar que mudam muito mais rapidamente no interior do que no exterior, o que significa estarmos queimando etapas. Nos primeiros quatro séculos de nossa história, vencemos um caminho correspondente a, pelo menos, quatro milênios da história europeia. A rigor, nossa história acompanha pari passu a história do capitalismo mundial, fazendo eco às suas vicissitudes. O mercantilismo nos descobriu, o industrialismo nos deu a independência, e o capitalismo financeiro, a república. 
$\mathrm{Na}$ economia e na sociedade brasileira a dualidade está em toda parte. Está na fazenda de escravos, que é mercantil e escravista, está no latifúndio pósabolição, que é mercantil e feudal (porque dominado pelo instituto da "meia"(ou enfiteuse) e pelo princípio feudal de que nenhuma terra deixará de ter senhor), está na fábrica capitalista, que enfrenta um mercado de insumos e um mercado para seus produtos ainda mercantil ou mesmo pré-capitalista. A partir daí, Rangel (1957, p. 32) define "a lei da dualidade": "[...] a economia brasileira se rege basicamente por duas ordens de leis tendenciais que imperam respectivamente no campo das relações internas de produção e no das relações externas de produção".

Para Rangel (1962, p. 220), a contrapartida política da dinâmica da dualidade reflete-se nos pactos de poder que se formam em torno do Estado, pois "o Estado brasileiro não pode senão refletir a dualidade básica da economia e da sociedade". Rangel analisa a história econômica e política do Brasil, a partir do século XIX, como uma sucessão de dualidades, que correspondem a fases de declínio e expansão de ciclos de Kondratieff. O início de cada dualidade corresponde ao início da fase "b" dos sucessivos ciclos longos de Kondratieff. E corresponde também a um fato político dominante: a Independência, na primeira dualidade; a Abolição e a República, na segunda; a Revolução de 1930, na terceira. Em cada dualidade, o polo secundário corresponde, internamente, à relação de produção já dominante nas sociedades mais avançadas, e se transformará na relação de produção dominante, ou seja, no polo principal da dualidade seguinte. Em relação aos "sócios", ocorre o mesmo processo. O sócio menor de uma dualidade se transformará no sócio maior da seguinte.

No trabalho de 1981, em que Rangel atualizou sua teoria de 1953, ele supunha que na quarta dualidade, que se definiria a partir de 1973 (o primeiro choque do petróleo e o fim dos "anos dourados" do capitalismo), o sócio maior seria a burguesia industrial, enquanto o menor seria formado pelos capitalistas financeiros. Na verdade, os empresários industriais já se haviam tornado os sócios maiores um pouco antes, entre 1930 e 1950. Por outro lado, seu tempo como sócio maior foi muito menor do que Rangel e todos os analistas previram. A partir de 1990 assistimos à interrupção da revolução nacional que, desde 1930, vinha transferindo para o Brasil as decisões sobre o interesse nacional. A partir de então, a dependência externa acentuou-se dramaticamente devido ao recurso ao crescimento com poupança externa e ao endividamento externo sem precedentes ocorrido nos anos 70, e repetido quase como farsa nos anos 90. Fragilizado pela crise, o setor real da economia, ao invés de se associar ao setor financeiro, como acontece nos países desenvolvidos, a ele se subordinou, ao mesmo tempo em que este se submetia aos rentistas locais e aos interesses dos países ricos. As políticas macroeconômicas dos governos brasileiros a partir de então, marcadas pela alta taxa de juros (que beneficia rentistas e o setor financeiro) e por taxa de câmbio 
valorizada (que beneficia multinacionais, que remetem lucros, e os países ricos) refletiram essa perversão. O resultado foi a semiestagnação entre 1980 e 2003 e o crescimento modesto desde então. Rangel não previu plenamente esses eventos, mas sua teoria da dualidade nos ajuda a compreendê-los.

\section{Considerações Finais}

Ignácio Rangel morreu em 1994, quando as nossas incertezas eram muito grandes a respeito do futuro do Brasil, depois de uma crise da dívida externa que se definiu em 1979 e se transformou em alta inflação inercial e crise fiscal do Estado. No ano, também, em que o êxito do Plano Real parecia indicar um futuro brilhante para o Brasil. Rangel era antes de tudo um otimista que acreditava nas potencialidades do Brasil. A inflação é um sintoma de crise, mas como a crise é cíclica, ela terá que ser superada na medida em que os recursos existentes nos setores com capacidade ociosa sejam transferidos para os novos setores dinâmicos. Então um novo padrão de financiamento do desenvolvimento afinal se delineará.

Rangel não teve tempo de presenciá-lo, mas seus discípulos e amigos não esquecerão seus ensinamentos e sua inspiração. No momento em que morreu, em 1994, talvez devessem pensar, como certamente Rangel lembraria, que a fase recessiva do quarto ciclo de Kondratieff devia estar se esgotando. De fato, o mundo capitalista a partir de então entrou em uma nova fase de prosperidade. Quase todos os países do mundo viram aumentar suas taxas de crescimento. Apenas a América Latina e particularmente o Brasil não se aproveitaram desse novo ciclo de expansão. Podemos supor que o que está havendo é apenas uma defasagem: que o Brasil também acabará se aproveitando da fase expansiva do quinto Kondratieff. Talvez, mas me parece mais correto usar aqui a teoria da dualidade para acentuar o desvio perverso ocorrido na última forma que essa dualidade tomou: a da subordinação do setor real da economia brasileira - da indústria e da agricultura - ao setor financeiro e aos rentistas associados aos interesses multinacionais. Em uma linguagem que não é a de Rangel, mas é minha, eu diria que essas ideias combinam com o colapso, ocorrido logo após a transição democrática de 1984, do último pacto político nacional que existiu no Brasil - o Pacto DemocráticoPopular de 1977, que comandará a transição democrática do Brasil em 1984. Com o fracasso do Plano Cruzado, porém, esse pacto entra em colapso, e o espaço é aberto para a adoção da ortodoxia convencional - o conjunto de diagnósticos e propostas que os países ricos fazem aos países em desenvolvimento. O domínio dessa ortodoxia implicava a aliança dos rentistas e do setor financeiro local com os países ricos, e a renúncia a uma estratégia nacional de desenvolvimento. Ora, como Rangel sempre soube, sem estratégia nacional não é possível o desenvolvimento. Rangel foi um nacional-desenvolvimentista; hoje o Brasil precisa de um 
novo pacto econômico e político e de um novo desenvolvimentismo se quiser voltar a crescer.

\section{Referências}

BRESSER-PEREIRA, L. C. A crise financeira global e depois. Um novo capitalismo? Novos Estudos Cebrap, n. 86, p. 51-72, 2010. . Lucro, acumulação e crise. São Paulo: Brasiliense, 1986.

BRESSER-PEREIRA, L. C.; REGO, J. M. Um mestre da economia brasileira: Ignácio Rangel. Revista de Economia Política, v. 13, n. 2, p. 98-119, 1993.

KONDRATIEFF, N. The long wave cycle. New York: Richardson $\mathcal{E}$ Snyder, 1984. Primeira edição russa, 1925. Este livro é uma tradução da edição russa de 1928.

RANGEL, I. M. A dinâmica da dualidade brasileira. Revista Brasileira de Ciências Sociais, v. 2, n. 2, p. 215-235, jun. 1962.

. A dualidade básica da economia brasileira. Rio de Janeiro: Instituto Superior de Estudos Brasileiros, 1957. de ensaios).

Ciclo, tecnologia e crescimento. Rio de Janeiro: Civilização Brasileira, 1982. (Coleção

. Elementos de economia do projetamento. Salvador: Livraria Progresso Editora, 1960. Curso ministrado em 1958. Reeditado por Editora Bienal, 1987.

. O Brasil na fase "b" do 4o. Kondratieff. In: 330. CONGRESSO DA SOCIEDADE BRASILEIRA PARA O PROGRESSO DA CIÊNCIA, 33., 1981, São Paulo. Anais... São Paulo: SBPC, 1981. P. 15-43.

. Obras Reunidas. Rio de Janeiro: Contraponto, 2005. (Dois volumes, organização de César Benjamin).

Perspectivas econômicas brasileiras para a próxima década. In: REUNIÃO ANUAL $\overline{\mathrm{DA}}$ SOCIEDADE BRASILEIRA PARA O PROGRESSO DA CIÊNCIA, 24., 1972, São Paulo. Anais... São Paulo: SBPC, 1972. p. 44-62. 1985.

Recessão, inflação e dívida externa. Revista de Economia Política, v. 5, n. 3, p. 5-25,

SOLOMOU, S. Phases of Economic Growth - 1850-1973. Cambridge: Cambridge University Press, 1990.

Recebido em: 14/08/2012.

Aceito em: 10/11/2012. 